\title{
Central $B_{2}$ receptor involvement in the antinociceptive effect of bradykinin in rats
}

\author{
II.R. Pelá, *A.L. Rosa, C.A.A. Silva \& †J.P. Huidobro-Toro \\ Laboratory of Pharmacology, Faculty of Pharmaceutical Sciences of Ribeirão Preto, University of São Paulo, SP, Brazil; \\ *Department of Dental Surgery, Faculty of Dentistry of Ribeirão Preto, University of São Paulo, SP, Brazil and †Laboratory of \\ Pharmacology, Neurohumoral Regulation Unit, Department of Physiology, Pontificia Universidad Católica de Chile
}

1 The effect of intracerebroventricular (i.c.v.) injection of bradykinin (BK) and related peptides was tested on the dental pulp electrical stimulation threshold (DPEST) in rats.

2 BK (4, 8 and $16 \mathrm{nmol})$ induced a dose-dependent increase of DPEST, indicative of an antinociceptive effect.

3 I.c.v. injection of equimolar doses of BK-related peptides, Lys-BK and Met-Lys-BK, also induced an increase of DPEST, but the magnitude of the effect was not as intensive as that induced by BK, when the maximum increase of DPEST was considered. The peptide T-kinin induced a short lasting and weak antinociceptive effect.

4 The $\mathrm{B}_{1}$ agonist, des-Arg'-BK $(8 \mathrm{nmol})$ induced a significant antinociceptive effect, but this was not as intensive as that induced by $B K$.

5 The $\mathrm{B}_{2}$ antagonist $\mathrm{D}-\mathrm{Arg}^{0}-\mathrm{Hyp}^{3}-\mathrm{Thi}^{5,8}-\mathrm{D}-\mathrm{Phe}^{7}-\mathrm{BK}\left(\mathrm{D}-\mathrm{Arg}^{0}\right.$ ) competitively antagonized the $\mathrm{BK}$-induced antinociception. Likewise, $\mathrm{Hyp}^{3}-\mathrm{Thi}^{5,8}-\mathrm{D}-\mathrm{Phe}^{7}-\mathrm{BK}$ (Hyp) also antagonized BK effect. However, the compound $\mathrm{Thi}^{5,8}$-D-Phe $-\mathrm{BK}$ (Thi), initially considered a pure BK antagonist, induced an antinociceptive effect, supporting previous observations that this peptide can also act as a partial agonist.

6 It is concluded that the dose-dependent antinociceptive effect induced by i.c.v. injection of BK is mediated by the stimulation of brain $B_{2}$ receptors.

Keywords: Kinins; bradykinin; antinociceptive effect; $B_{1}$ receptor; $B_{2}$ antagonist

\section{Introduction}

Bradykinin (BK) is a nonapeptide (Arg-Pro-Pro-Gly-Phe-SerPro-Phe-Arg) cleaved by enzymes (kallikreins) from certain proteins (kininogens) that circulate in the plasma and are present in different tissues or glands. BK exerts a variety of biological actions and has been implicated in the pathogenesis of inflammation, pain, asthma, hypertension and other diseases (for a review see Bhoola et al., 1992). Many reports have described the presence of the enzymes involved in the synthesis and degradation of BK (Chao et al., 1983; 1987; Richoux et al., 1991) as well as BK-immunoreactive neurones (Corrêa et al., 1979; Perry \& Snyder, 1984; Kariya et al., 1985) in the central nervous system (CNS). More recently, specific, high-affinity binding sites for BK have also been demonstrated in the brain (Fujiwara et al., 1988) and in cultured neuronal cells (Lewis et al., 1985). Cholewinski et al. (1991) have shown that astrocytes possess specific, high-affinity binding sites for BK and that these are predominantly of the $B_{2}$ subtype.

BK has been suggested to act as a modulator and neurotransmitter in the CNS (Graeff, 1971; Kariya et al., 1985; Miller, 1987). Previous studies have shown that intracerebroventricular (i.c.v.) or intracerebral injection of BK causes marked behavioural and somatic effects in experimental animals. These include: sedation and catatonia (Corrado et al., 1960; DaSilva \& Rocha e Silva, 1971), noradrenaline depletion (Graeff et al., 1969), hyperthermia (Almeida e Silva \& Pelá, 1978; Mohan Rao \& Bhattacharya, 1988), hypertension (Corrêa \& Graeff, 1975; Lindsey et al., 1989; Fior et al., 1993), antidiuretic-hormone release (Rocha e Silva, Jr \& Malnick, 1964), antiaversive effect (Burdin et al., 1992) and antinociception (Ribeiro et al., 1971; Ribeiro \& Rocha e Silva, 1973; Laneuville \& Couture, 1987; Laneuville et al., 1989).

The present study was carried out in order to investigate the

${ }^{1}$ Author for correspondence at: Laboratory of Pharmacology, Faculty of Pharmaceutical Sciences of Ribeirão Preto, USP, Av. do Café, S/N, 14040-903-Ribeirão Preto, SP, Brazil. antinociceptive effect induced by i.c.v. injection of BK and related kinins on the dental pulp electrical stimulation threshold (DPEST) in rats. Since kinins bind to specific receptors that are present in some areas of the brain and belong to two major categories, designated as $B_{1}$ and $B_{2}$, the effects of specific agonists and antagonists on the response induced by BK were also investigated.

\section{Methods}

\section{Animals}

Male Wistar rats weighing $150-180 \mathrm{~g}$ were used. They were housed in individual cages with continuous access to food and water and maintained on a $12 \mathrm{~h}$ light-dark cycle. Two days before the experimental session, each rat was handled and habituated to the testing procedures, except that neither dental pulp electrical stimulation nor the i.c.v. injection was undertaken.

\section{Surgery}

The animals were anaesthetized with sodium pentobarbitone (45 mg kg ${ }^{-1}$, i.p.) and a $10 \mathrm{~mm}$ length 23 -gauge stainless-steel guide cannula was implanted in the lateral ventricle according to Corrêa \& Graeff (1974). The guide cannula and two steel screws were permanently secured to the skull with dental cement. Each cannula was kept patent with a sterile obturator. After receiving an intramuscular injection of a veterinary penicillin, the animals were housed individually and one week was allowed before the experiments.

\section{Procedures}

Two days before the dental pulp electrical stimulation test, the animals were anaesthetized with sodium pentobarbitone 
(30 $\mathrm{mg} \mathrm{kg}^{-1}$, i.p.) and two cavities of $1 \mathrm{~mm}$ diameter were made laterally, one in each of the two superior incisors, $2 \mathrm{~mm}$ below the level of the gingival margin. These cavities were deepened just for the placement of electrodes. A forcepsshaped electrode consisted of a platinum wire with a diameter of $1 \mathrm{~mm}$ at the end and covered, except at the tip, with enamel to avoid short circuiting by saliva. This procedure was carried out because stimulation of extradental afferents also elicits a jaw-opening reflex. In order to determine the threshold, the electric current, delivered by a stimulator, was increased stepwise from a subthreshold value until eliciting a response characterized by the jaw-opening reflex. Electric parameters were: duration of $2 \mathrm{~ms}$, frequency of $2 \mathrm{~Hz}$ and variable current $(\mu \mathrm{A})$ applied for $1 \mathrm{~s}$.

Animals were tested every $5 \mathrm{~min}$, until a stable baseline DPEST was obtained and then for up to $60 \mathrm{~min}$ following microinjection of drugs. Each DPEST was normalized by an index of analgesia (IA) using the formula:

$$
\mathrm{IA}=\frac{(\text { test DPEST })-(\text { average baseline DPEST })}{(\text { average baseline DPEST })}
$$

The results were expressed as means of IA values against time of readings, IA values of the maximum response against treatments or area under the curves (computer units).

\section{Drugs}

Drugs were diluted in sterile saline and injected in a $5 \mu \mathrm{l}$ volume over a $1 \mathrm{~min}$ period with a stainless-steel needle $(70 \mu \mathrm{m}$ o.d.) inserted into the guide cannula immediately before the microinjection.

The following drugs were used: BK (Fundap-SP, Brazil), Lys-BK, Met-Lys-BK, T-kinin (Sigma, U.S.A.) and the bradykinin-antagonists Thi, Hyp and D-Arg ${ }^{\circ}$ (see Table 1), synthesized by solid phase methodology at the University of Colorado, Health Sciences Center, Denver (U.S.A.) and kindly donated by Dr J.M. Stewart.

\section{Statistical analysis}

The dose-response curves were assessed by regression analysis and statistical analysis was achieved by one-way ANOVA followed by the Duncan's test using SPSS statistical software. Comparisons of single groups were made by Student's twotailed unpaired $t$ test. $P$ values less than 0.05 were regarded as significant. All values are presented as mean \pm s.e.mean.

\section{Results}

\section{Effect of i.c.v. injection of bradykinin on DPEST}

Bradykinin (1-8 nmol, i.c.v.) induced a dose-dependent increase in DPEST (Figure 1). The optimal antinociceptive effect was observed $15 \mathrm{~min}$ after i.c.v. injection of BK and the duration of the effect was also related to the dose. In another experiment, which evaluated the effect of $B_{2}$ antagonist on BKinduced antinociception, a significant linear regression $[\mathrm{y}=0.82(\log \mathrm{x})+0.0078, \quad r=0.98, P=0.003]$ was obtained when the maximum response induced by BK $(1-16 \mathrm{nmol})$ was considered (Figure 2). One-way ANOVA test showed a significant influence of the treatment $\left(F_{5,21}=9.9306, P<0.001\right)$, although only the doses of 4,8 and $16 \mathrm{nmol}$ caused a significant effect (Duncan's test, $P<0.05$ ).

\section{Blockade of the BK-induced antinociception by $\mathrm{B}_{2}$ receptor antagonists}

Concomitant i.c.v. injection of $\mathrm{D}-\mathrm{Arg}^{0}(8 \mathrm{nmol})$ reduced the antinociceptive effect (maximum response) induced by BK, shifting the dose-response curve to the right. A significant linear regression was obtained $[\mathrm{y}=1.30(\log \mathrm{x})-1.20, r=0.99$, $P=0.009$ ] (Figure 2). One-way ANOVA test showed a significant influence of the treatment $\left(\mathrm{F}_{3,15}=6.7351, P<0.0065\right)$. Parallelism test revealed that the parallel nature of the dis-
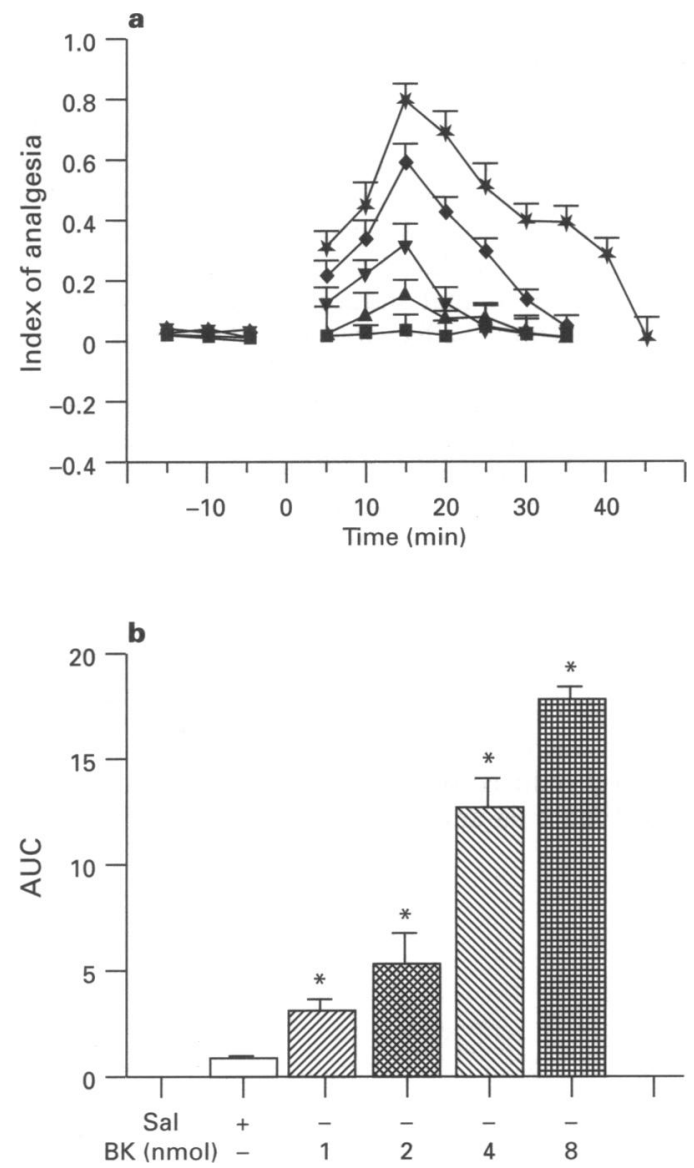

Figure 1 (a) Time course of the dose-dependent increase in DPEST induced by i.c.v. injection of BK, represented by the index of analgesia: $(\Delta) 1 \mathrm{nmol}(n=5) ;(\nabla) 2 \mathrm{nmol}(n=5) ;(\diamond) 4 \mathrm{nmol}(n=6)$; $(\star) 8 \mathrm{nmol}(n=5) ;(\square)$ saline $(n=4)$. (b) Area under the curve of the groups shown in $(a)$. ${ }^{*}$ Significantly different from saline $(P<0.05)$.

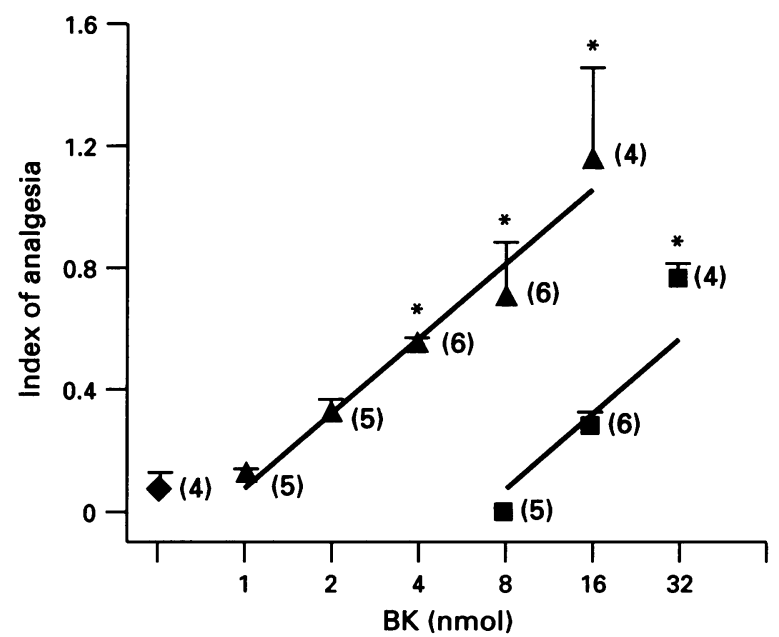

Figure 2 Effect of D-Arg ${ }^{0}$ on BK-induced analgesia: (A- $\left.\mathbf{A}\right)$ shows the maximum response induced by i.c.v. injection of different doses of BK; $(\square-\square)$ indicates the maximum response induced by concomitant i.c.v. injeciton of $\mathrm{BK}$ and D-Arg ${ }^{\circ}(8 \mathrm{nmol}) ;(\diamond)$ indicates the response induced by saline. Number of animals in each group is indicated in parentheses. *Significantly different from saline $(P<0.05)$. 
placement is significant $(t=1.96, P<0.05)$. The Schild plot obtained from these results was linear (with a slope equal to $1.3 \pm 0.11$, Figure 3) and gave a nominal $\mathrm{pA}_{2}$ value of 8.28 (8.11 - 8.45). Concomitant i.c.v. injection of Hyp ( $8 \mathrm{nmol})$ also antagonized the antinociceptive effect induced by BK ( $4 \mathrm{nmol})$ (Figure 4). Neither D-Arg ${ }^{0}$ nor Hyp (8 nmol, i.c.v.) changed the DPEST.

\section{Antinociceptive effect of bradykinin-related compounds}

Table 1 shows the primary amino acid sequence of BK and related compounds that were tested on DPEST. Figure 5 shows the antinoceptive effect of BK ( $4 \mathrm{nmol}$, i.c.v.) as well as the agonist effect of the alleged pure BK antagonist (Thi, $7.5 \mathrm{nmol}$, i.c.v.). Thi induced an antinociceptive effect with a magnitude similar to that induced by BK. A small but significant antinociceptive effect was also observed after the i.c.v. injection of the $B_{1}$ agonist, des-Arg'-BK $(8 \mathrm{nmol})$.

The effects of the i.c.v. injection of equimolar doses (8 $\mathrm{nmol}$ ) of some BK analogues, Lys-BK and Met-Lys-BK, on DPEST were also investigated. Both peptides induced an antinociceptive effect with a maximum response observed 10 to $15 \mathrm{~min}$ after i.c.v. injection (Figure 6a). The maximum response induced by Lys-BK and Met-Lys-BK was less marked than that exhibited by BK (Figure 6a), but the effects of the three peptides were similar when the integrated response (area under curve) was considered (Figure 6b). T-kinin, a kininaseresistant peptide present in the rat brain, induced a small and short lasting response, significantly different in magnitude from the effect induced by BK and structurally related peptide analogues (Figure 6a and b).

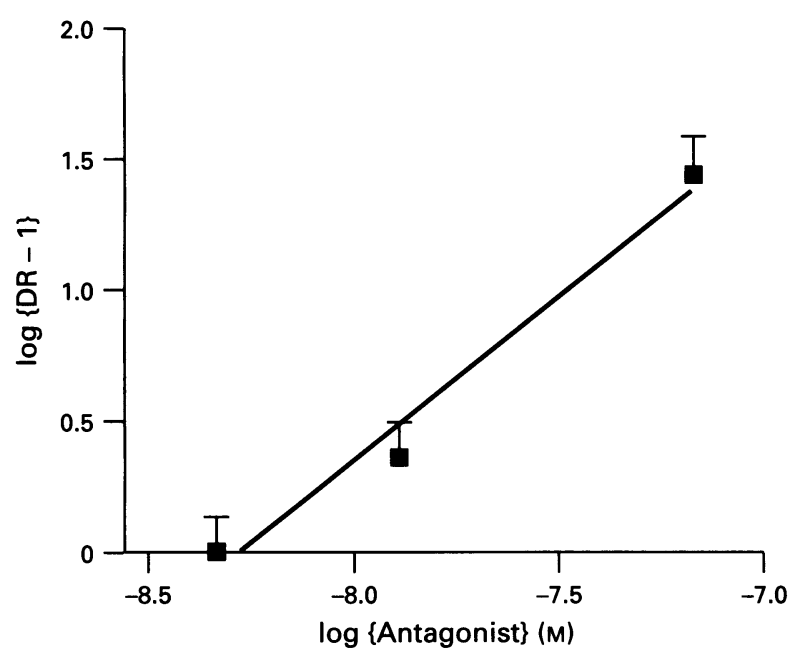

Figure 3 Schild analysis of the data demonstrating that D-Arg ${ }^{0}$ is a potent competitive functional antagonist of $\mathrm{BK}$-induced analgesia. Slope was 1.3 and the intercept on the abscissa scale was 8.28.

\section{Discussion}

The present data show that the i.c.v. injection of BK induces a dose-dependent antinociceptive effect in rats, as indicated by an increase in DPEST. These results give support to previous findings that BK induces a dose-related antinociceptive effect in rats assessed by the rat tail-hot wire technique (Laneuville \& Couture, 1987; Mohan Rao \& Bhattacharya, 1988; Laneuville et al., 1989). The response induced by BK was competitively antagonized by $\mathrm{D}-\mathrm{Arg}^{\mathrm{O}}$. The dose-response curve obtained after the i.c.v. injection of BK, in the presence of $\mathrm{D}-\mathrm{Arg}^{0}$, is indicative of a competitive antagonism, since the antagonist
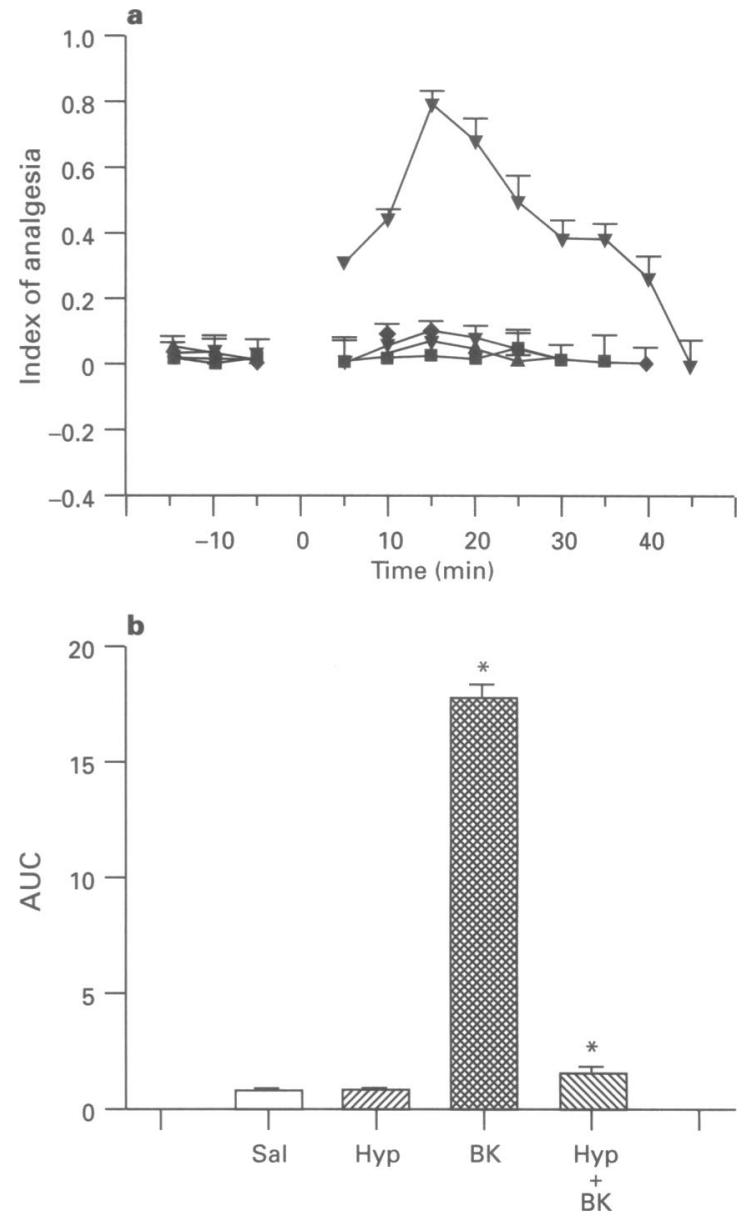

Figure 4 (a) Effect of concomitant i.c.v. injection of Hyp on BKinduced analgesia. ( $\boldsymbol{\square}) \mathrm{Sal}(n=4) ;(\Delta) \mathrm{Hyp}, 8 \mathrm{nmol}(n=5) ;(\nabla) \mathrm{BK}$, $8 \mathrm{nmol}(n=5) ;(\diamond)$ Hyp, $8 \mathrm{nmol}+\mathrm{BK}, 8 \mathrm{nmol}(n=5)$. Data are represented by the index of analgesia. (b) Area under the curve of the groups indicated in $(a)$. ${ }^{*}$ Significantly different from BK $(P<0.05)$. \#Significantly different from saline $(P<0.05)$.

Table 1 Primary structures of BK and related compounds

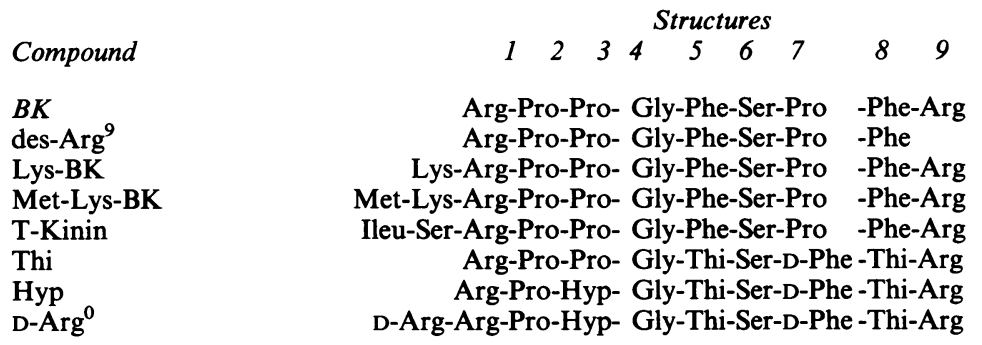

Thi:2-thienyl-L-alanine; Hyp: L-4-hydroxyproline. 
shifted the BK dose-response curve to the right and the Schild plot was linear with a slope equal to $1.3 \pm 0.12$. Regoli et al. (1993) suggested that the peptides D-Arg ${ }^{0}$, Thi and D-Arg ${ }^{0}$ Hyp $^{3}$-D-Phe - BK, early developed $B_{2}$ antagonists, also act as

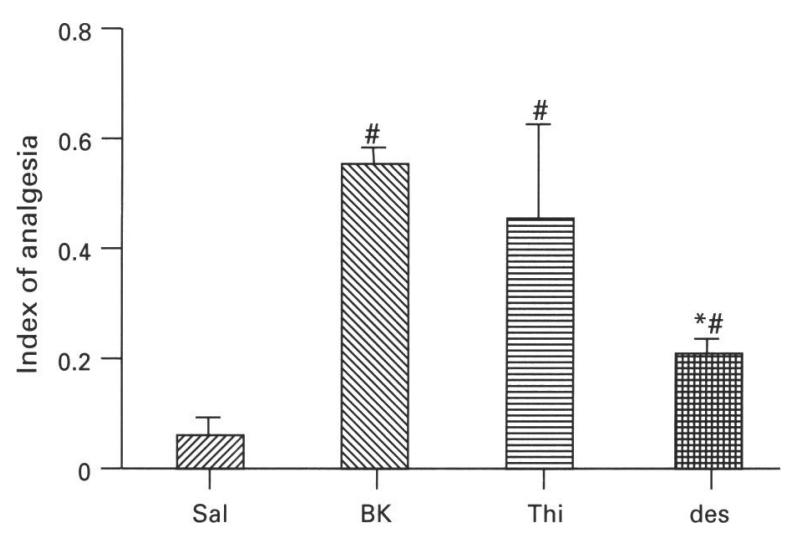

Figure 5 Effect of i.c.v. injection of $B K$ and some related compounds on DPEST, represented by the index of analgesia. Data are expressed as the mean \pm s.e.mean of the maximum response. Saline $(n=4)$, BK $(8 \mathrm{nmol}, n=5)$, Thi $(8 \mathrm{nmol}, n=5)$, des (des-Arg'BK; $8 \mathrm{nmol}, n=5)$. ${ }^{*}$ Significantly different from BK $(P<0.05)$. \#Significantly different from saline $(P<0.05)$.
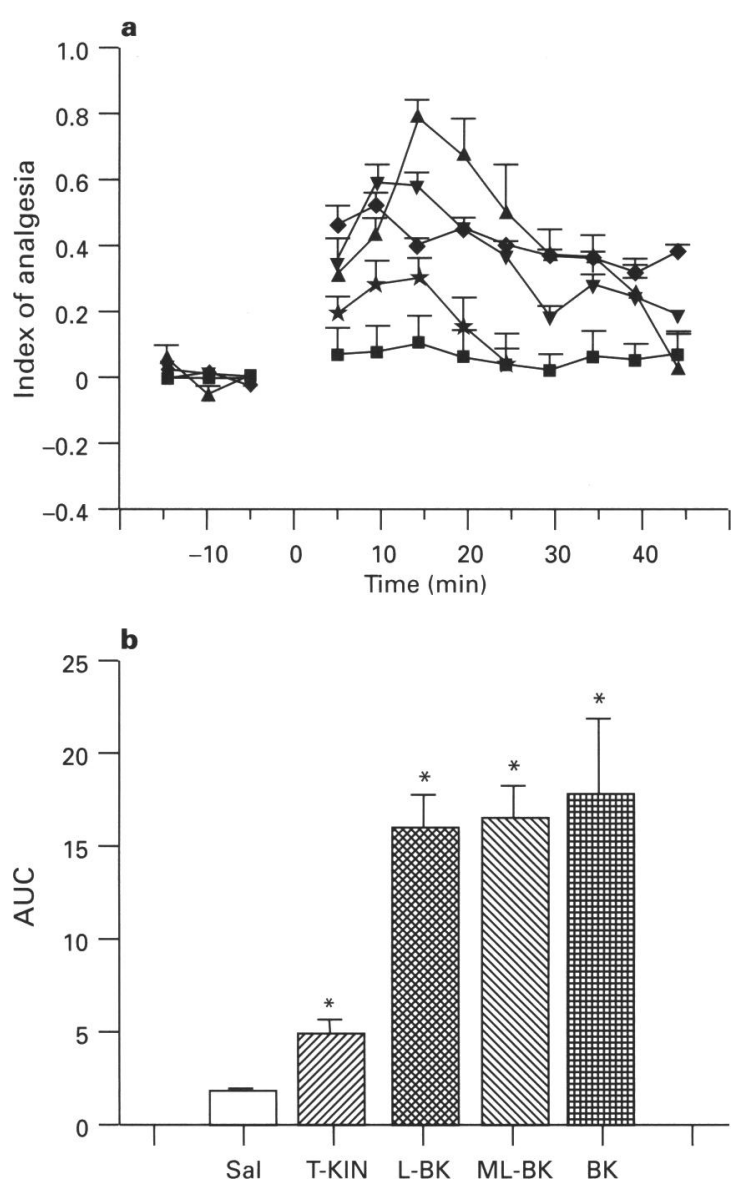

Figure 6 (a) Time course of the increase of DPEST induced by i.c.v. injection of BK and related compounds, represented by the index of analgesia. ( $\boldsymbol{\square})$ Saline $(\mathrm{Sal}, n=4) ;(\star)$ T-Kin $(8 \mathrm{nmol}, n=7) ;(\boldsymbol{\nabla}) \mathrm{L}-$ BK (8nmol, $n=4) ;(\diamond)$ ML-BK $(8 \mathrm{nmol}, n=5) ;(\boldsymbol{\Delta})$ BK $(8 \mathrm{nmol}$, $n=3$ ). (b) Area under the curve of the groups shown in (a). *Significantly different from saline $(P<0.05)$. partial agonists. Furthermore, the peptide D- $\mathrm{Arg}^{0}-\mathrm{Hyp}^{3}-\mathrm{D}-$ $\mathrm{Phe}^{7}-\mathrm{BK}$ acts as an antagonist at low concentrations $\left(10^{-7}-\right.$ $\left.10^{-8} \mathrm{M}\right)$ and as an agonist at high concentrations $\left(10^{-6} \mathrm{M}\right)$. In the present study, the inhibition of BK-induced antinociception by $\mathrm{D}-\mathrm{Arg}^{0}$ was obtained with doses in the range of $10^{-8} \mathrm{M}$, giving further support to its antagonist action. Therefore, the blockade of $\mathrm{BK}$ antinociceptive effect by a $\mathrm{B}_{2}$ antagonist and a $\mathrm{pA}_{2}$ equal to 8.28 are indicative that the antinociceptive effect of this peptide can be mediated by activation of $B_{2}$ receptors. Blockade of BK antinociceptive effect by Hyp, another $B_{2}$ antagonist, gives further support to the involvement of $B_{2}$ receptor activation in this response. Although the compound Thi has been previously suggested to act as a $B_{2}$ antagonist in some bioassays (Regoli et al., 1993), it also induced an antinociceptive effect with a magnitude similar to that induced by BK. This result suggests that Thi also acts as an agonist, at least in the dose used in the present study.

The $\mathrm{B}_{1}$ agonist, des-Arg'-BK, also induced a significant antinociceptive effect, but not as intensive as that induced by BK. This may lead to the suggestion that part of the BKantinociceptive effect may also involve activation of $B_{1}$ receptors, since BK is rapidly cleaved to des-Arg'-BK in the CNS (for a review, see Bhoola et al., 1992).

Depending on the kind of kininogen and cleavage specificity of the protease involved, four types of kinins can be generated: the nonapeptide BK, the decapeptide kallidin (Lys-BK), and the undecapeptides Met-Lys-BK and lle-Ser-BK (T-kinin) (for a review see Bhoola et al., 1992). Although the rat brain presents immunoreactivity only for BK (Corrêa et al., 1979; Perry \& Snyder, 1984; Kariya et al., 1985), we investigated the effect of Lys-BK, Met-Lys-BK and T-kinin on DPEST, as their precursors, the high molecular weight kininogen and T-kininogen, have been characterized in this tissue (Richoux et al., 1991). In spite of small differences among the maximum increases of DPEST induced by i.c.v. injection of $8 \mathrm{nmol} / \mathrm{rat}$ of $\mathrm{BK}$ and related peptides, no differences were found when the integrated responses (area under the curve) were analysed. These results indicate that the antinociceptive effect of Lys-BK and Met-Lys-BK might be due to peptide cleavage to BK by brain kininases. However, the earlier maximum response induced by these peptides when compared to BK may also indicate that these peptides have intrinsic antinociceptive activity. On the other hand, the weak antinociceptive effect of T-kinin may be related to its low susceptibility to kininases, as has been described by Okamoto \& Greenbaum (1983). To date, the only established role for this kinin is mediation of the inflammatory response in rats (Barlas et al., 1985; Sakamoto et al., 1987).

Bradykinin is classically recognized to cause a decrease in blood pressure after systemic administration. However, i.c.v. injection of BK causes a persistent increase in the mean arterial pressure in rats (Corrêa \& Graeff, 1975; Lindsey et al., 1989). A similar effect has been observed after injection of BK into the lateral septal area (Corrêa \& Graeff, 1975) or in areas adjacent to the ventral portion of the third ventricle (Lewis \& Phillips, 1984). Fior et al. (1993) also showed that BK injection into the dorsal and dorsal lateral surfaces of the medulla induced an increase in the mean arterial blood pressure, with the highest pressor effect observed after injection of the peptide into the medial part of the nucleus tractus solitarius. Unpublished results from our laboratory (Couto, personal communication) showed that the injection of BK into the fourth ventricle and locus coeruleus induced an antinociceptive effect, but a pressor response was observed only when BK was injected into the fourth ventricle. These results suggest that the BK-antinociceptive effect is not secondary to its hypertensive action.

In summary, the present results indicate that i.c.v. injection of $\mathrm{BK}$ induces a dose-dependent antinociceptive effect in rats by stimulating $B_{2}$ receptors in the brain. These results give support to the proposal that BK may be an important modulator of nociceptive process in the CNS, since it induces an antinociceptive effect after central injection in rats, as assessed 
by different algesimetric methods. The central sites and the mechanisms that are involved in the antinociceptive effect of BK represent the principal purpose of future studies.

\section{References}

ALMEIDA E SILVA, T.C. \& PELÁ, I.R. (1978). Changes in rectal temperature of the rabbit by intracerebroventricular injection of bradykinin and related kinins. Agents Actions, 8, 102-107.

BARLAS, A., OKAMOTO, H. \& GREENBAUM, L.M. (1985). Tkininogen - the major plasma kininogen in rat adjuvant arthritis. Biochem. Biophys. Res. Commun., 129, 280-286.

BHOOLA, K.D., FIGUEROA, C.D. \& WORTHY, K. (1992). Bioregulation of kinins: kallikreins, kininogens, and kininases. Pharmacol. Rev., 44, $1-80$

BURDIN, T.A., GRAEFF, F.G. \& PELÁ, I.R. (1992). Opioid mediation of the antiaversive and hyperalgesic actions of bradykinin injected into the dorsal periaqueductal gray of the rat. Physiol. Behav., 52, 405-410.

CHAO, J., CHAO, L., SWAIN, C.C., TSAI, J. \& MARGOLIUS, H.S (1987). Tissue kallikrein in rat brain and pituitary: regional distribution and estrogen induction in the anterior pituitary. Endocrinology, 120, 475-482.

CHAO, J., WOODLEY, C., CHAO, L. \& MARGOLIUS, H.S. (1983). Identification of tissue kallikrein in brain and in the cell-free translation product encoded by brain mRNA. J. Biol. Chem., 258, $15173-15178$.

CHOLEWINSKI, A.J., STEVENS, G., MCDERMOTT, A.M. \& WILKIN, G.P. (1991). Identification of $B_{2}$ bradykinin binding sites on cultured cortical astrocytes. J. Neurochem., 57, 1456-1458.

CORRADO, A.P., RAMOS, A.O. \& ROCHA E SILVA, M. (1960). On possible central effects of bradykinin in the cat. Acta Physiol. Latinoamer., 9, 222.

CORRÊA, F.M.A. \& GRAEFF, F.G. (1974). Central mechanisms of the hypertensive action of intraventricular bradykinin in the unanaesthetized rat. Neuropharmacology, 13, 65-75.

CORREAA, F.M.A. \& GRAEFF, F.G. (1975). Central site of the hypertensive action of bradykinin. J. Pharmacol. Exp. Ther., $192,670-676$

CORRÊA, F.M.A., INNIS, R.B., UHL, G.R. \& SNYDER, S.H. (1979). Bradykinin-like immunoreactive neuronal systems localized histochemically in rat brain. Proc. Natl. Acad. Sci. U.S.A., 76, $1489-1493$.

DA SILVA, G.R. \& ROCHA E SILVA, M. (1971). Catatonia induced in the rabbit by intracerebral injection of bradykinin and morphine. Eur. J. Pharmacol., 15, 180-186.

FIOR, D.R., MARTINS, D.T.O. \& LINDSEY, C.J. (1993). Localization of central pressor action of bradykinin in medulla oblongata. Am. J. Physiol., 265, H1000-H1006.

FUJIWARA, Y., MANTIONE, C.R. \& YAMAMURA, H.I. (1988) Identification of $\mathbf{B}_{2}$ bradykinin binding sites in guinea-pig brain. Eur. J. Pharmacol., 147, 487-488.

GRAEFF, F.G., PELÁ, I.R. \& ROCHA E SILVA, M. (1969). Behavioural and somatic effects of bradykinin injected into the cerebral ventricles of unanaesthetized rabbits. Br. J. Pharmacol., 37, 723732.

GRAEFF, F.G. (1971). Kinins as possible neurotransmitters in the central nervous system. Ciência Cultura, 23, 465-473.

KARIYA, K., YAMAUCHI, A. \& SASAKI, T. (1985). Regional distribution and characterization of kinin in the CNS of the rat. J. Neurochem., 44, 1892-1897.
We are indebted to Dr M.M. Coelho for reviewing the manuscript and many helpful discussions.

LANEUVILLE, O. \& COUTURE, R. (1987). Bradykinin analogue blocks bradykinin-induced inhibition of a spinal nociceptive reflex in the rat. Eur. J. Pharmacol., 137, $281-291$.

LANEUVILLE, O., READER, T.A. \& COUTURE, R. (1989). Intrathecal bradykinin acts presynaptically on spinal noradrenergic terminals to produce antinociception in the rat. Eur. J. Pharmacol., 159, 273-283.

LEWIS, R.E. \& PHILLIPS, M.I. (1984). Localization of the central pressor action of bradykinin to the cerebral third ventricle. Am. J. Physiol., 247, R63-R68.

LEWIS, R.E., CHILDERS, S.R. \& PHILLIPS, M.I. (1985). $\left[{ }^{125} \mathrm{I}\right] \mathrm{Tyr}$ bradykinin binding in primary rat brain cultures. Brain Res., 346, $263-272$.

LINDSEY, C.J., NAKAIE, C.R. \& MARTINS, D.T.O. (1989). Central nervous system kinin receptors and the hypertensive response mediated by bradykinin. Br. J. Pharmacol., 97, 763-768.

MILLER, R.J. (1987). Bradykinin highlights the role of phospholipid metabolism in the control of nerve excitability. Trends Neurosci. $10,226-228$

MOHAN RAO, P.J.R. \& BHATTACHARYA, S.K. (1988). Hyperthermic effect of centrally administered bradykinin in the rat: role of prostaglandins and serotonin. Int. J. Hyperthermia, 4, 183-189.

OKAMOTO, H. \& GREENBAUM, L.M. (1983). Isolation and structure of T-kinin. Biochem. Biophys. Res. Commun., 112, $701-708$.

PERRY, D.C. \& SNYDER, S.H. (1984). Identification of bradykinin in mammalian brain. J. Neurochem., 43, $1072-1080$.

REGOLI, D., JUKIC, D., GOBEIL, F. \& RHALEB, N.-E. (1993) Receptors for bradykinin and related kinins: a critical analysis. Can. J. Physiol. Pharmacol., 71, 556-567.

RIBEIRO, S.A., CORRADO, A.P. \& GRAEFF, F.G. (1971). Antinociceptive action of intraventricular bradykinin Neuropharmacology, 10, 725-731.

RIBEIRO, S.A. \& ROCHA E SILVA, M. (1973). Antinociceptive action of bradykinin and related kinins of larger molecular weights by the intraventricular route. Br. J. Pharmacol., 47, 517-528.

RICHOUX, J.P GELLY, J L., BOUHNIK, J., BAUSSANT, T , ALHENC GELAS, F., GRIGNON, G. \& CORVOL, P. (1991). The kallikreinkinin system in the rat hypothalamus. Immunohistochemical localization of high molecular weight kininogen and $\mathrm{T}$ kininogen in different neuronal systems. Histochemistry, 96, 229-243.

ROCHA E SILVA, JR., M. \& MALNIC, G. (1964). Release of antidiuretic hormone by bradykinin. J. Pharmacol. Exp. Ther. 146, $24-32$.

SAKAMOTO, W., FUMIHIKO, S., KATSUHIRO, G. \& UEHARA, S (1987). Ile-Ser-bradykinin (T-kinin) and Met-Ile-Ser-bradykinin (Met-T-kinin) are released from T-kininogen by an acid proteinase of granulomatous tissues in rats. Fed. Eur. Biochem. Soc., 219, 437-440.

(Received August 14, 1995 Revised February 26, 1996 Accepted March 27, 1996 